Artículos

\title{
Abrir el archivo. Reflexiones sobre la investigación en un archivo de información policial
}

Open the file. Reflections on the investigation in a police information archive

Maria Celeste Schnyder

DOI: https://doi.org/10.24215/18537863e073

CONICET. Universidad Nacional de Santiago del Estero

(UNSE). Instituto de Estudios para el Desarrollo Social.

Equipo de Estudios Socio-jurídicos en Derechos Humanos,

Argentina

celesteschnyder@gmail.com

Recepción: 31 Julio 2019

Aprobación: 06 Febrero 2020

\section{RESUMEN:}

El artículo reúne reflexiones sobre una experiencia de vinculación entre universidad, ministerio público fiscal y organismos de derechos humanos para la investigación del fondo documental de la Sección Archivo del Departamento de Informaciones Policiales de Santiago del Estero. El texto revisa las particularidades del proceso de investigación analizando las condiciones que posibilitaron y limitan el acceso a su fondo documental; los aportes de la historia, la archivística y la antropología para producir los corrimientos epistemológicos necesarios para la lectura e interpretación de sus legajos más allá de la lógica policial y sus contribuciones potenciales para la investigación jurídica y académica.

Palabras Clave: Archivo policial, Etnografía, Versiones policiales.

\section{Abstract:}

The article gathers reflections on an experience of technological linkage between university, public prosecutor's office and human rights organizations for the investigation of the documentary collection of the Archive Section of the Department of Police Information of Santiago del Estero. The text reviews the particularities of the research process analyzing the conditions that made possible and limit access to its documentary collection; the contributions of history, archives and anthropology to produce the epistemological shifts necessary for the reading and interpretation of its files beyond police logic and its potential contributions for legal and academic research.

KEYWORDS: Policial archive, Ethnography, Police versions.

\section{INTRODUCCIÓN}

Los procesos vinculados a la demanda de Memoria, Verdad y Justicia de Argentina han logrado la realización en tribunales federales con asiento en las provincias de los juicios por delitos de lesa humanidad ocurridos durante la última dictadura cívico-militar. Esta conquista ha generado una renovada demanda de investigaciones académicas en torno al pasado reciente y, en el caso que ocupa este artículo, de los llamados archivos de la represión.

En ese marco el Ministerio Público Fiscal de la Nación, junto a organismos de derechos humanos (DDHH), han promovido y producido distintas formas de cooperación con diferentes universidades del país para producir información potencialmente útil para el avance de estas causas judiciales. La desclasificación de

\section{Notas DE AUTOR}

Investigadora del Consejo Nacional de Investigaciones Científicas y Técnicas, Argentina (CONICET). Profesora de la Universidad Nacional de Santiago del Estero (UNSE). Coordinadora del Equipo de Estudios Socio-jurídicos en Derechos Humanos del Instituto de Estudios para el Desarrollo Social (UNSE-CONICET).

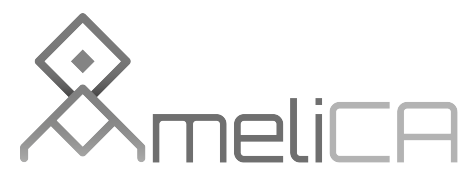


documentación burocrático administrativa de las fuerzas de seguridad conservada en los archivos militares y policiales ha contribuido a echar luz sobre algunas acciones y sobre las jerarquías, funciones y responsabilidades de quienes llevaron a cabo la represión, ofreciendo indicios sobre estructuras, recursos, cadenas de mando, etc. (Memoria Abierta, 2011, pp. 8-9).

En el marco de ese proceso más amplio, en Santiago del Estero fue suscripto en junio de 2014 un Convenio de Cooperación y Asistencia Científica y Tecnológica entre el Ministerio Público Fiscal (MPF), con asiento en la provincia, con el Instituto Espacio para la Memoria (IEM) y la Asociación por la Memoria, la Verdad y la Justicia de Familiares de Detenidos Desaparecidos y Ex Presos Políticos y la Facultad de Humanidades, Ciencias Sociales y de la Salud (FHCSyS) de la Universidad Nacional de Santiago del Estero (UNSE). Dicho convenio tiene por objeto la producción de conocimiento relativo a la violación de DDHH en base al análisis del material documental y testimonial existente en la provincia, con el fin de contribuir a la investigación judicial en el marco de las causas de lesa humanidad que tramitan en la provincia. Para ello fue conformado un equipo integrado por miembros del IEM y del MPF, becarios/as e investigadores/as del Instituto de Estudios para el Desarrollo Social (INDES) de la UNSE, del cual soy parte. Uno de los objetivos de esa colaboración es relevar el fondo documental de la Sección Archivo del Departamento de Informaciones Policiales de Santiago del Estero (en adelante DIPSE), que llegó a acumular alrededor de 40 mil carpetas de legajos mientras estuvo activo entre 1972-2004.

Este artículo busca presentar la propuesta metodológica construida para llevar adelante el relevamiento del archivo del DIPSE. Para ello expondré en primer lugar las condiciones particulares bajo las cuales se despliega el proceso de investigación que posibilitaron y, a la vez, limitan el acceso a su fondo documental. En segundo lugar revisaré algunos procesos históricos-políticos que impulsaron el desarrollo de agencias y capacidades estatales con el objeto de reunir, clasificar, conservar información, y que, a nuestro entender, resultan centrales para dotar de sentido al análisis de sus lógicas clasificatorias y técnicas de averiguación de antecedentes. En tercer lugar, en base a los aportes producidos por la historia, la archivística y la antropología, que permiten abordar al archivo como artefacto cultural, se presenta un análisis preliminar de sus legajos.

\section{Sobre LAS CONDICIONES y OBJETIVOS INICIALES DEL ACCESO AL DIPSE}

Las condiciones de acceso y objetivos iniciales, bajo los cuales ingresamos al archivo, son aspectos que hacen al desarrollo de la estrategia metodológica para el abordaje de un fondo de documentos policiales que fueron durante tres décadas confidenciales, secretos y reservados.

El DIPSE fue creado por decreto del gobierno de la intervención militar en 1972 y fue clausurado el 6 de marzo del año 2004, luego de su allanamiento por orden de la Justicia Federal en razón de la presentación de habeas data por parte de ciudadanos santiagueños. En el acta de allanamiento se encuentran registrados 17 ficheros metálicos que contienen alrededor de 40 mil legajos de personas, 2 ficheros con fichas patronímicas, 2 ficheros con fichas organizadas por domicilios, una caja fuerte cerrada, que a la fecha sigue sin abrirse, la documentación de los tres armarios ubicados en la oficina guardada en 15 cajas de cartón (por ejemplo carpetas de panoramas ambientales diarios relativas a las novedades registradas en distintas localidades de la provincia y a organizaciones/instituciones). Desde ese momento este fondo documental se encuentra bajo la custodia de la justicia federal, en tanto es considerado como elemento de prueba de las distintas causas de lesa humanidad que tramitan en la provincia.

Desde su allanamiento y durante aproximadamente un año la documentación permaneció en el mismo sitio con el objeto de que las personas pudieran recuperar sus legajos previa presentación de habeas data. En el año 2005 fue trasladado a un depósito del Puesto Móvil N. 5 de Gendarmería Nacional, en donde fue alojado también el acervo documental de otro organismo que prestó servicios de inteligencia en la provincia, la Subsecretaria de Seguridad (1995-2004). Desde entonces solo accedían oficiales de justicia a retirar legajos con una orden del Juez a requisitoria de la fiscalía o por interposición de habeas data. 
Junto al equipo de trabajo tomamos contacto con el archivo por primera vez en 2014. Cuando ingresamos al depósito de gendarmería nos encontramos con una escena marcada por los estragos que la humedad y la falta de aire pueden causar sobre materiales como el papel guardado dentro de un depósito oscuro. Decidimos no entrar hasta que el olor se evanesciera. Lo que vimos después fue impactante, no tanto por el desorden en que quedaron dispuestos los ficheros, cajas y paquetes luego del traslado realizado por hombres de la gendarmería. Sino porque el cielorraso se había desplomado sobre ellos como consecuencia de la humedad y ahí nos fue evidente que la sala se inundaba cada vez que había una llovía abundante, herrumbrando los ficheros metálicos, humedeciendo los documentos contenidos en los cajones próximos al suelo, sumergiendo los que estaban en él. Como han señalado Caimari y Nazar (2015), los archivos argentinos, y en la provincia no era una excepción, han sido objeto de la desidia y/o el abandono estatal.

Las deficientes condiciones en las que se encontraba la documentación y las evidencias del deterioro acelerado nos impulsaron a emprender una serie de gestiones para su preservación, como ser: la reubicación de los fondos documentales en las instalaciones del ex DIPSE y su señalización como sitio de Memoria con el objetivo de mejorar las condiciones de guarda (mayo de 2016); la articulación con el Archivo Nacional de la Memoria para la Digitalización de algunos documentos seleccionados en el relevamiento para su incorporación a la causa judicial.

Nuestra primera aproximación al archivo tuvo la finalidad de identificar y recuperar documentación que aportara información relativa al proceso represivo en la provincia y su contexto histórico. Entre los aspectos de interés se encuentran la composición de la comunidad informativa activa en el área y subzona; el circuito institucional administrativo que sustentó a la producción de información e inteligencia y su rol en la estrategia represiva; las cadenas de mando; la participación de actores policiales, militares o judiciales; entre otros.

Estos objetivos iniciales fueron centrales para organizar el relevamiento en un contexto en el cual la ausencia de un archivero-arconte parecía determinante para la comprensión del archivo. En su obra Mal de ArchivoDerrida (1997) describe a los arcontes como lugar de autoridad, generalmente estatal, ostentado por quienes les fue delegado el derecho y la competencia para interpretar los archivos. Esa ausencia pareció inicialmente una desventaja porque el fondo documental se nos presentaba como una realidad caótica, no tanto por el cúmulo de documentación, sino por la ajenidad con ese mundo que es un archivo policial y su lenguaje. Ajenidad que podría pensarse como el reverso de la opacidad construida por la institución policial como resultado de que su misión es intrínseca al ejercicio estatal de la soberanía y por el cual estos documentos obtenían su estatuto de reservados, confidenciales y secretos. Ann Laura Stoler (2010) en "Archivos coloniales y el arte de gobernar" sostiene que es necesario cambiar el enfoque del archivo-comofuente al archivo-como-objeto. Esto supone abordarlos como lugares de producción de conocimiento (más que de extracción de información), como artefactos culturales de producción de "hechos", de taxonomías y de la autoridad estatal.

Bajo esta perspectiva perdía centralidad la ausencia de un archivero-arconte en tanto nuestra presencia en el archivo no era la del intérprete. Se trataba más bien de indagar en los procesos que hicieron posible la práctica del acopio policial de información para uso político, en las capacidades estatales -con sus técnicas y procedimientos- que fueron desarrolladas con ese fin, en los criterios empleados para demarcar qué era o no importante de registrar y documentar, sobre quiénes se escribían informes.

¿Pero por dónde comenzar la indagación? A diferencia del archivo de la DIPBA, ${ }^{1}$ los ficheros del DIPSE no están organizados por "mesas de trabajo" y "factores", sino en función de la numeración de legajos personales asignada en el momento en que era iniciada la investigación de antecedentes. Esto hizo que no nos fuera posible reconocer a priori los criterios y características de las poblaciones bajo control policial.

Inclusive la progresión cronológica de la acumulación de los legajos puede llevar a la idea de que la práctica del registro de informaciones políticas se circunscribió a un determinado periodo de funcionamiento institucional. 
La observación de los legajos da cuenta de que ellos contienen referencias cruzadas a otros fondos documentales de organismos que lo antecedieron. Por ejemplo, pudimos identificar documentación producida por otras reparticiones políticas o policiales que se ocuparon en distintos momentos históricospolíticos del país y la provincia del registro de información sobre personas. Nos referimos a la Oficina de Coordinación de Informaciones (década del 50), Secretaría de Informaciones del Estado y Contralor (década del 50), la Sección de Orden Social y Político de la División de Investigaciones (década del 50), la Dirección de Coordinación y Enlace - delegación local SIDE- (décadas del 60 y 70). Este hallazgo no solo pone de relieve el largo aliento del interés gubernamental por el control ideológico de la población, sino también la premisa metodológica de que para comprender un archivo es necesario conocer las instituciones a las que este ha servido. La policía, sea por su larga historia de vigilancia de poblaciones específicas, o por las necesidades simbólicas de su relación con la sociedad, es una de las agencias del Estado con mayor y temprano interés en la producción, sistematización y resguardo de archivos, coadyuvando inclusive a la génesis y evolución de las propias capacidades estatales (Caimari y Nazar, 2015, p. 2). La comprensión de un archivo demanda además conocer aquellos procesos históricos-políticos que han contribuido a su creación y que dotan de sentido a los criterios que determinaron qué era o no pertinente registrar; qué comportamientos, con qué clasificaciones y procedimientos se describían conductas como sospechosas. En el apartado siguiente daremos cuenta de algunos de los procesos que impulsaron el desarrollo de agencias dedicadas a la reunión, clasificación, conservación de informaciones políticas y en particular a la creación del DIPSE.

\section{CONTROL SOCIAL, REPRESIÓN Y ARCHIVOS}

La creación del DIPSE puede ser enmarcado en dos grandes procesos. El primero y más evidente es el proceso represivo que tuvo lugar en la segunda mitad del s. XX, especialmente en la década del setenta. Esta relación entre represión y archivos ha sido tematizada bajo la expresión Archivos de la Represión.

En 1995 el Consejo Internacional de Archivos (ICA) de UNESCO empleó esta denominación para designar a los documentos producidos en el desenvolvimiento de distintos regímenes represivos del mundo. $\mathrm{Al}$ momento de iniciar nuestro relevamiento del DIPSE, las investigaciones antecedentes en torno a este tipo de archivos dejaron trazado un sendero. La publicación en el año 2002 de Los Archivos de la represión: documentos, memoria y verdad de Elizabeth Jelin y Ludmila da Silva Catela aportó a la configuración de un campo de estudios situado en la intersección entre los estudios sobre el llamado pasado reciente, los trabajos de la memoria, y el activismo jurídico por los derechos humanos. Allí se los define como

(un) conjunto de objetos secuestrados a las víctimas o producidos por las fuerzas de seguridad (policías, servicio de inteligencia, fuerzas armadas) en acciones represivas (allanamientos, persecución, secuestro, tortura, desaparición, asesinatos, etc.) perpetradas durante las últimas dictaduras militares en los países del Cono Sur (da Silva Catela, 2002, pp. 209-210).

Pueden comprender distintos tipos de acervos: los archivos producidos por instituciones represivas del Estado, los repositorios acumulados por organizaciones de derechos humanos y Comisiones por la Verdad, y otra documentación dispersa sobre el periodo dictatorial.

Los documentos de archivo pueden considerarse como la sedimentación o testimonio de la actividad continuada de una institución o persona en el desarrollo de sus funciones (Nazar, 2007). Tal vez por esto una de las visiones predominantes fue la de los archivos como territorio de memoria (da Silva Catela, 2002), abriendo la discusión respecto de las políticas de conservación y accesibilidad (Jelin, 2002), los usos para la investigación judicial y como garantía de derechos (Olmo, 2002; Nazar, 2007 y 2010), las posibilidades y dilemas en el uso de archivos con información sensible devenidos en públicos (Caimari y Nazar, 2015). Asimismo, el estudio de la DIPBA ha sustentado una serie de investigaciones focalizadas en comprender la historia del organismo y su modo de funcionamiento durante la dictadura (Funes, 2004 y 2006; Jaschek y Funes, 2005), las representaciones subyacentes en algunas de sus categorías clasificatorias (Kahan, 2010; Marengo, 
2015) y las comunidades discursivas presentes en sus documentos (Vitale, 2017). Barreneche (2010) ha planteado algunas advertencias sobre lo que se puede encontrar en las fuentes históricas institucionales de la policía debido a "su status moral ambiguo (selección de documentos que favorecen el papel de la policía), la inaccesibilidad (por vía de la retención u ocultamiento de la información) y la simulación (o manipulación)" (p. 3). Pero, en la medida que en ellos se trasluce la operatividad y el funcionamiento de, por ejemplo, la policía de investigaciones, pueden constituirse en fuente para la Memoria Histórica.

Visto en una perspectiva más amplia este tipo de archivo no es solo la producción documental generada en un determinado periodo como la dictadura, sino el emergente de un proceso represivo (Nazar, 2007) que cobra sentido en relación a los conflictos en torno a la consolidación y hegemonización del Estado argentino.

Gabriela Águila (2013) define a la represión como "la violencia estatal y paraestatal orientada a reprimir la conflictividad social y política y/o la violencia insurgente que se verificó hacia los años 70” (p. 2). La historiadora sostiene lo que llama una perspectiva estructural centrada en el estudio de las agencias estatales y paraestatales involucradas en el accionar represivo, los dispositivos y dinámicas puestos en práctica. Desde esta perspectiva la represión, si bien alcanzó un punto de inflexión en la última dictadura, fue el emergente de las continuidades, vínculos y rupturas respecto del accionar represivo ejecutado en los años previos. Esto es particularmente evidente en relación a los organismos de inteligencia.

El registro de las continuidades y, con ello, el establecimiento de genealogías respecto de la vigilancia, el control y la dinámica de la persecución política realizada por el Estado o sus agencias a lo largo de varios décadas y regímenes políticos ha sido postulada certeramente para analizar a los servicios de inteligencia que habían comenzado a actuar bastante antes del golpe de Estado en la detección y seguimiento de las potenciales víctimas del accionar represivo (Águila, 2013, p. 3).

En efecto, la acumulación de informaciones políticas sobre personas puede ser vinculada a la consolidación del Estado nacional, el gobierno de la otredad y la construcción de discursos identitarios. Ese proceso más amplio dio lugar a la articulación de políticas de control social que impulsaron el desarrollo de capacidades estatales y técnicas de identificación y averiguación de antecedentes que sentaron las condiciones de posibilidad para la creación de organismos como el DIPSE.

El mantenimiento del orden público ha sido una de las funciones que dio impulso en el periodo posindependentista a la formación de policías abocadas a la administración de la convivencia y la conflictividad en las ciudades. El primer Departamento de Policía en Santiago del Estero data de junio de 1832; desempeñaba funciones relativas al "bien común”, “orden” y “aseo" de la ciudad y de auxiliar de justicia. Además desempeñaba funciones de control poblacional en los obrajes (unidad de producción forestal de la provincia con características de organización colonial) a través de la policía de campaña.

Hacia fines de s. XIX, y en el marco de la consolidación del Estado nacional, fueron emergiendo agencias estatales específicas para la gestión de los asuntos municipales, salubridad, justicia de paz, por ejemplo, que posibilitaron que la policía comenzara un proceso hacia una organización centralizada y enfocada en seguridad. Ese proceso fue correlativo a la necesidad de organizar un aparato destinado a reprimir la disidencia política (Kalmanowiecki, 2003, citada en Galeano, 2007). En efecto, la inmigración que estaba transformando las ciudades trajo consigo la preocupación de las elites gobernantes por las ideas del anarquismo y el comunismo.

En ese marco el proyecto de Estado nación se apoyó, entre otras políticas, en un diseño político criminal centrado en la identificación de personas (Galvani, 2016). Las ideas del higienismo social y del positivismo criminológico fueron empleadas por las elites gobernantes para justificar, modernizar, promover el conocimiento de personas, fueran o no delincuentes, habilitado por la hipótesis sobre la peligrosidad social.

En consecuencia, durante la primera mitad del s. XX se produjo el desarrollo de aparatos administrativos para reunir, clasificar, conservar información. A través de ese proceso se fueron inscribiendo en las rutinas policiales las concepciones positivistas sobre las causales individuales del delito y la peligrosidad como resultante del ambiente. 
La persecución ideológica promovida por los gobiernos conservadores de la década de 1930, en especial contra el comunismo, consolidaron el lugar de la policía de investigaciones dentro de las fuerzas de seguridad.

Durante estos años, la policía tenía incorporada una función de vigilancia política, esperándose de ella los informes sobre reuniones públicas y actividades de los dirigentes de la oposición, todo lo cual formaba parte de sus reportes oficiales y memorias anuales (Barreneche y Galeano, 2008, pp. 87-88).

El advenimiento del peronismo a mediados de la década del 40, siguiendo a Barreneche y Galeano (2008), dio lugar a una fase madura del proceso de profesionalización de las policías especializadas en seguridad. Las claves del cambio de la organización policial en las provincias -cuyo objetivo central fue romper los lazos entre las autoridades policiales locales y los dirigentes políticos (fundamentalmente conservadores y radicales) - fueron la centralización, el reforzamiento de la autoridad jerárquica y el afianzamiento del sistema de escalafones de acuerdo a los lineamientos del orden y la doctrina militar.

En ese marco en Santiago del Estero fue creada en 1950 la División de Investigaciones de la Jefatura de Policía, que comprendía a las Comisarías Seccionales, con funciones de seguridad y defensa. Bajo su órbita funcionó la sección Gabinete de Identificaciones y la Sección de Orden Social y Político. En nuestro relevamiento en el archivo del DIPSE encontramos carpetas de legajos identificados con la letra C pertenecientes a dicha Sección. Estas contienen informes de personas consideradas comunistas y dan cuenta de la constitución de la cuestión ideológica como asunto de seguridad provincial.

Como es sabido, el interés por el control ideológico se vio profundizado en el contexto de la Guerra Fría. La circulación de la Doctrina de la Seguridad Nacional (DSN), y particularmente la Doctrina de Guerra Revolucionaria (DGR) francesa, colocaron a la inteligencia en el centro de la estrategia de la represión del enemigo interno.

El concepto de guerra revolucionaria, o guerra ideológica, sustituyó al de guerra convencional entre Estados delimitados por sus espacios nacionales; del mismo modo, la idea de soberanía dejó de aludir a las fronteras geográficas para referirse a las ideológicas y políticas (...) El concepto de enemigo interior pasó a hallarse vinculado a todo individuo, grupo u organización susceptible de servir, directa o indirectamente, a intereses opuestos al interés nacional. Y, por carácter transitivo, la población en su conjunto era percibida como parte de ese enemigo, o como su base de apoyo (Chiarini y Portugheis, 2014, pp. 46-47).

Desde la perspectiva castrense la guerra revolucionaria era la vía utilizada por el comunismo y sus aliados para tomar el poder en el mundo occidental. "Debido a que era llevada adelante por un 'enemigo interno' que se mimetizaba con la multitud, el principal objetivo para las fuerzas del orden lo constituía el control de la población" (Summo y Pontoriero, 2012, p. 288). En ese marco la Secretaría de Inteligencia del Estado (SIDE), primer órgano estatal de información e inteligencia ${ }^{2}$ creado por decreto 2985 de abril de 1961, asumió la función de "planificar, dirigir y supervisar la acción del Estado en materia de comunismo y otros extremismos" (Sain, 1997, p. 146). El organismo tuvo sus propias delegaciones en algunas ciudades (Córdoba, Corrientes, Mendoza, Neuquén, Rosario, Tucumán), así como funcionarios acreditados en distintas provincias que dirigían los departamentos de Enlace o Informaciones (Águila, 2013). En nuestro relevamiento identificamos el funcionamiento de la Oficina de Coordinación y Enlace y que sus informes de antecedentes contienen referencias cruzadas a documentación producida por la Sección de Orden Social y Político.

Hacia 1972, en los prolegómenos de la instalación del terrorismo de Estado, el III Cuerpo del Ejército ordenó el asentamiento del Batallón de Ingenieros de Combate 141 y de un "órgano adelantado" del Destacamento de Inteligencia $142^{3}$ para el control de la subzona a la que pertenecía Santiago del Estero. En ese contexto el interventor militar de la provincia, Carlos Jensen, dispuso la creación en 1972 del DIPSE. Este departamento, identificado bajo el código D-2, forma parte de la estructura de las policiales provinciales y fueron uno de los organismos integrantes de las comunidades informativas del ejército creadas en cada una de las zonas, subzonas y áreas que abastecían al Batallón de Inteligencia 601 (desde 1973 unidad de centralización de inteligencia), a las Jefaturas correspondientes, y luego accionaban, a través de los Grupos 
de Tareas, las directivas que se impartieran (Ministerio de Justicia y Derechos Humanos. Programa Verdad y Justicia, Informe "Batallón de Inteligencia 601", p. 20).

Este despliegue territorial de funciones de vigilancia, registro y circulación de informes tuvo como condición de posibilidad la preexistencia de capacidades, técnicas y documentación de archivo de los organismos que antecedieron al DIPSE.

\section{El archivo como artefacto}

El cruce entre la disciplina archivística, la historia y la perspectiva etnográfica en el marco del llamado giro archivistico (Derrida, 1997; Farge, 1991; Gorbach y Rufer, 2016; Stoler, 2010) ha generado propuestas metodológicas sumamente fértiles para los estudios basados en diferentes documentos producidos por burocracias estatales. La antropología jurídica ha contribuido a enriquecer el estudio de archivos y otros documentos estatales, como los expedientes judiciales, al plantear ir «más allá del documento» para dilucidar la trama de relaciones sociales, traducidas en prácticas, valores, tradiciones, costumbres, conflictos y actores, que son parte integrante y constitutiva de las instituciones del Estado (Sarrabayrouse Oliveira, 2009).

El enfoque etnográfico ha permitido constituir a los documentos estatales en un campo de indagación en sí mismo al considerarlos como emergentes de prácticas escritas de las instituciones estatales. De este modo el documento puede ser analizado como resultante de las relaciones sociales y de poder (Muzzopappa y Villalta, 2011).

El desplazamiento desde el enfoque del archivo-como-fuente al archivo-como-objeto, además de estas consideraciones etnográficas, despierta consideraciones de orden epistemológico.

El giro archivístico en el campo de los estudios poscoloniales ha puesto de relieve la cuestión de las políticas de conocimiento en las que se basan las prácticas estatales coloniales (aun las poscoloniales). Stoler refiere a un escepticismo epistemológico por el cual ha sido posible reflexionar de manera crítica

sobre la elaboración de documentos y sobre cómo decidimos utilizarlos, sobre los archivos no como lugares de recuperación del conocimiento, sino de producción del mismo, como monumentos estatales y sitios para la etnografía del Estado. Esto no constituye un rechazo a los archivos coloniales como fuentes del pasado. Más bien, apunta hacia un compromiso constante con tales archivos como artefactos culturales (Stoler, 2010, p. 469).

De este modo el archivo deja de ser considerado un sitio inerte de almacenamiento y conservación donde ocurre una operación extractiva, para ser explorado como objeto, como la expresión material de una epistemología, con sus sistemas de clasificación, utilizados bajo condiciones sociales y políticas específicas, que conforman y reflejan las características esenciales de la política y el poder estatal colonial. En este punto Stoler avanza aún más y agrega que la producción de archivos implica un proceso de inscripción de las relaciones de poder y una tecnología de gobierno. Por tanto, los archivos pueden ser considerados además como un agente de producción de la autoridad estatal (p. 465).

Los estudios poscoloniales y decoloniales han puesto de relieve esta relación poder y archivo.

El Estado-Nación (occidental, poscolonial, latinoamericano) tiene una relación paradójica con el archivo. Por un lado, no hay estado sin "sus" archivos que lo legitimen y le den plena existencia en el continuo temporal. Por otro, el archivo es una amenaza latente para el estado. El propio registro de pugnas, voces diversas y subversiones a la legitimidad y al orden se vuelven una amenaza al sentido mismo de su legitimidad (Rufer, 2016, p. 166).

Estas consideraciones nos llevan a la operación archivística, su epistemología y clasificaciones por las cuales se define, registra y produce un saber institucionalmente legitimado en torno a determinados sujetos, comportamientos, prácticas sociales, relaciones sociales (significándolos desde discursos securitarios y marcos interpretativos que instalaron la tesis de las fronteras ideológicas y los enemigos internos). Como advierte Stoler (2010) los archivos producen tanto como registran los hechos que en apariencia solo dicen describir. Inclusive, el análisis del contenido de los archivos no debe perder de vista que "no sólo se trata de algo que es 
(objeto, texto, imagen), sino de lo que es por investidura previa: quien lo guarda, lo constituye en original y le infunde la capacidad de hablar por el acontecimiento" (Rufer, 2016, p. 165).

Señalar la condición de artefactual de los archivos supone reconocerlos como "una tecnología que se destina a producir asociaciones entre personas, eventos, espacios y cosas, y no solamente para almacenar informaciones sobre su pre-existencia" (Gomes Da Cunha, 2010, p. 110).

Como señala Eilbaum (2004) las versiones son una forma de construcción de los hechos que tienen un efecto de verdad, una verdad policial, en torno a la cual se desplegarán luego distintas formas de intervención policial/judicial. Una versión policial que da cuenta, no de cómo "fueron los hechos", sino de cómo han sido escritos para ser presentados ante el aparato militar / judicial. Entonces, más que de encontrar verdades objetivas, nuestro trabajo en el archivo está más próximo al estudio de los procesos que allí se encuentran objetivados.

Esto tiene centralidad para nuestra labor porque el interés inicial que posibilitó nuestro acceso al archivo del DIPSE fue el de identificar documentos con valor probatorio. Es decir, el archivo se nos presentaba como una fuente donde extraer documentos que, desde la lógica judicial, contendrían "verdades" probatorias o evidencia de responsabilidad en los delitos cometidos durante la dictadura. Ese objetivo colaborativo establecido en el marco de la vinculación con el IEM y el MPF ha permitido producir aportes concretos a las causas a partir de la identificación de documentación, la elaboración de informes relativos al contexto histórico provincial incorporados al proceso mediante la figura de testigo de contexto y en la instancia de los alegatos, etc. Pero, a su vez, la lógica de la prueba judicial instala al archivo como fuente y en la ilusión positivista que supone "la creencia en que el contenido de los textos y objetos históricos refleja linealmente el mundo y sus interrelaciones" (Muzzopappa y Villalta, 2011).

El abordaje etnográfico ha permitido construir nuestro vínculo epistemológico con el archivo desde un registro diferente más allá de las propiedades y la literalidad de los documentos. A su vez reponer la condición de artefacto cultural que reviste y constituye a los archivos nos ha llevado a explorar aspectos vinculados a la escritura de los legajos, entendiendo que ellos resultan de un proceso que se vale de técnicas policiales, discursos científicos y sociales, y leyes para la construcción narrativa de sujetos de intervención disciplinante/ represiva.

Las investigaciones de Lila Caimari son iluminadoras respecto de los usos del positivismo para la cientifización de las técnicas policiales (2012). Las carpetas de legajos del DIPSE están hechas de un conjunto de fichas impresas en la tapa, dorso y contratapa. Una es la ficha de filiación que, además de los datos civiles, incluye una descripción morfológica y cromática. La ficha de identificación incorpora los supuestos de la antropometría, impresiones digitales y la fotografía orientadas a desentrañar el posible futuro delictual.

Si bien la mirada del positivismo criminológico se encuentra en el núcleo de las técnicas de identificación, observamos que los legajos están predominantemente sustentados con otras técnicas orientadas a la averiguación de antecedentes. Esto supone más que el conocimiento del presente legal de una persona reconstruido a través de la incorporación al legajo de la planilla de Prontuario y de Información sobre los Procesos judiciales y las Contravenciones federales. La indagación policial busca establecer otros "riesgos" vinculados a la amenaza de la delincuencia política o ideológica. La concepción castrense sobre la amenaza de un enemigo interno, legalizada y legitimada con la sanción de tipos penales a través de la Ley N. 20.840 (1974) o de los llamados "decretos de aniquilamiento" de la subversión (N. 261 de febrero de 1975; N. ${ }^{\circ} 2770$, N. ${ }^{\circ} 2771$ y N. ${ }^{\circ} 2772$ de octubre del mismo año), circuló también en el plano del discurso social, alimentando y reforzando la construcción de estereotipos sociales. Esto es visible en los informes ambientales.

El informe ambiental, también llamado socio-ambiental, es una técnica compartida con otras profesiones como el trabajo social. Incluye prácticas que van desde la visita domiciliaria, entrevistas entre los vecinos, el registro de notas, la valoración de la información, la escritura de un informe (Lijterman, 2015). Llevado al terreno policial el procedimiento está asociado con una intervención encubierta. Es vigilancia del domicilio más que una visita amable y se vale de la indagación informal entre los vecinos y los dichos del barrio. 
La nombrada está catalogada entre los vecinos, políticamente de distintas maneras: unos dicen que es comunista, otros que milita las filas del ERP o que pertenece a los Montoneros, pero siempre se deduce que posee ideas comunistas. Vive actualmente en la calle XX N. ${ }^{\circ} 801$, en donde suelen buscarla personas mayormente joven en horas de la noche principalmente. Es una persona a la cual le gusta vestir bien y a la moda. Su concepto moral en el barrio es muy bajo. La nombrada es alumna irregular de abogacía en la Universidad y trabaja como maestra en Villa Giménez. También se tiene conocimiento que la causante abandona su hogar los fines de semana sin poder precisar su destino. Santiago del Estero, octubre 31 de 1974. C-16 (Cuaderno de campo, 20 de agosto de 2015).

Los ambientales se nutren también de la delación entre personas que se conocen.

en el día de la fecha, de fuentes que merecen fe, se tuvo conocimiento que en la sección contaduría de la división local de Agua y Energía, se produjo una discusión entre el contador de la misma, sr. A, y el causante, en razón de que este solicitó permiso para salir a realizar unas gestiones y que marcaría en vale de salida, a lo que el sr. A contestó que esto ya no está permitido. Ante la negativa el causante le dijo al sr. A. "como ahora apoya a estos botudos podridos que poco a poco nos están quitando todos los beneficios”. Informe del 23.2.77 (Cuaderno de campo, 22 de mayo de 2017).

La sustancia de la que están hechos los ambientales pone el foco en la arbitrariedad que los constituye y nos demanda un trabajo de análisis y deconstrucción de la mirada policial; un examen de los criterios que definen cuáles informaciones serían "políticas" y cuáles no, la elección y legitimación de las fuentes; los usos del discurso del enemigo interno para procesar y legitimar intervenciones policiales. También se nos hizo evidente que la discrecionalidad, rasgo inherente al poder policial, se expande cuando se trata de este tipo de procedimientos. La valoración de la información y la decisión de asignar a una persona determinada clasificación se encuentra en el criterio del agente de calle. Y esas concepciones policiales se encuentran atravesadas por patrones de dominación basados, por ejemplo, en ideas de jerarquía entre géneros, entre otros.

Comprender la lógica seguida por la policía para decidir el inicio de una investigación de antecedentes sobre una persona ha supuesto desentrañar parte de sus procedimientos burocráticos habituales.

La primera vía de entrada fue acudir al reglamento del DIPSE, pero pronto nos encontramos dos limitaciones. Una vinculada al carácter reservado, confidencial y secreto que envuelve a la actividad de los servicios de informaciones e inteligencia del Estado. Frente a esto exploramos dos caminos.

El primero fue recurrir a la analogía como método de interpretación que posibilita "una comprehensión 'como si' de lo menos inteligible por lo más inteligible" (Geertz, 1991). En ese sentido, las investigaciones en torno al fondo documental de la Dirección de Inteligencia de la Policía de la Provincia de Buenos Aires (DIPBA) han sido aportes valiosos para la comprensión de su estructura orgánica y funciones de organismos análogos como el DIPSE. Su desclasificación y puesta en acceso para la consulta pública ha sustentado una serie de investigaciones fundamentales para iluminar aspectos funcionales y operativos del organismo. La creación de estos departamentos de informaciones en el seno de las policías provinciales, también conocidos como D2, responden a un proceso general de militarización de las fuerzas de seguridad y la consecuente resignificación de la defensa nacional como hipótesis de seguridad interior. La cuestión del enemigo interno sin dudas tuvo un lugar central en la estructuración del funcionamiento de los servicios de informaciones en tanto la estrategia represiva estuvo basada en la inteligencia. En ese marco las secciones de informaciones de las policías comenzaron a participar en un sistema nacional de inteligencia, adoptando para sí objetivos e hipótesis de conflicto propios de las Fuerzas Armadas por los cuales había que detectar y detener "subversivos". ¿Qué sentidos adquiría la persecución del enemigo interno en una provincia como Santiago del Estero, periférica en términos políticos y económicos, en la cual no se registró un proceso de movilización social y radicalización política de la magnitud e intensidad que recorrió a los grandes centros urbanos del país en las décadas del 60 y 70 del siglo XX?

Esto nos llevó a explorar un segundo camino consistente en indagar en los procesos de criminalización primaria de la segunda mitad del siglo XX. De la lectura de los legajos surge que la investigación de antecedentes fue una práctica de rutina aplicada especialmente en relación a empleados públicos y autoridades y miembros de comisiones directivas de diferentes instituciones. En el primer caso para discernir 
posibles antecedentes ideológicos y eventualmente ofrecer "pruebas" o consolidar sospechas, y en el segundo para actualizar novedades e identificar posibles amenazas. La investigación solía finalizar con la emisión de un certificado de antecedentes con el sello con alguna de las tres categorías posibles: "favorable", "no recomendable", "desfavorable". Esa regularidad en la práctica de la averiguación de antecedentes se nos hizo inteligible a partir de identificar la vigencia de la ley de calificación ideológica N. ${ }^{\circ} 17401 / 67$ que facultaba a la SIDE, así como a los servicios de informaciones y demás reparticiones públicas vinculadas, a realizar la calificación de personas físicas o ideales, previendo una serie de inhabilitaciones y penas privativas de la libertad en el caso de "actividades comprobadas de indudable motivación ideológica comunista”. La vigencia de esta ley hizo que "en cierta medida estar en las clasificaciones estatales pasó de ser un símbolo de delincuencia a un necesario certificado de ciudadanía” (Galvani, 2016, p. 138).

Pero encontramos producción documental que no responde al seguimiento de rutina consecuencia del orden normativo. "Al causante se lo mantiene en observación a fin de verificar su ideología política por presumirse y según comentarios callejeros sería de la tendencia ideológica izquierdista" (cuaderno de campo sobre lectura de legajo N. ${ }^{\circ}$ 6676, 28 de noviembre de 2017), dice un legajo de octubre de 1962. La fórmula "mantener en observación" es empleada con frecuencia para esas intervenciones que se encuentran fuera de lo establecido. En ella subyace una de las formas en que históricamente ha sido ejercido el poder de policía como es la sospecha. "Inscripta en la práctica y legitimada en las leyes" la sospecha ha justificado y posibilitado distintas formas de proceder policial sin orden judicial alguna (Eilbaum, 2004).

Los legajos en donde la investigación de los antecedentes está movilizada por la sospecha se caracterizan porque parten de la hipótesis de culpabilidad, para luego ir hacia los hechos. Esta forma de intervención forma parte del repertorio de procedimientos disponibles y saberes policiales que están en la base de los procesos de criminalización secundaria. La exploración de los procesos de criminalización nos enfrentó a un segundo obstáculo vinculado a la idea de que las prácticas institucionales estarían gobernadas exclusivamente por la lógica normativa. El análisis documental nos indicaba que debíamos incluir en el análisis esas prácticas de oficio, las que además ayudan a comprender la continuidad que se observa en la actividad de los organismos de información e inteligencia. Entonces surgió como interrogante a explorar: ¿Cuál es la composición sociológica que adquiría el enemigo interno en la perspectiva y práctica de los agentes del DIPSE? ¿Qué otras figuras organizan la epistemología del archivo?

\section{Conclusiones}

La perspectiva etnográfica nos permitió expandir los límites de la lógica del documento-prueba propio de la investigación judicial que, por otra parte, nos posibilitó el acceso al archivo. El giro archivístico puso de relieve el cuestionamiento sobre el conocimiento y sus relaciones con las instituciones de validación del saber. En consecuencia, la investigación sobre los archivos debe partir de la premisa de que este no habla por sí mismo a menos que sea interrogado, y de que sus documentos son la objetivación de discursos sociales y prácticas empleadas en otros contextos históricos para el gobierno de la conflictividad social.

Esta prevención cobra una especial relevancia en relación a los archivos policiales de informaciones empleadas para la represión y el control social. La propia definición de sus informes en términos de información tiene el efecto de colocar a sus legajos como meras descripciones objetivas, invisibilizando que durante el proceso de investigación de antecedentes se construyen también versiones policiales. Versiones que luego habilitan y justifican diferentes formas de intervención de la policía, sea disciplinante o represiva, sobre determinadas poblaciones.

Estas consideraciones nos llevaron a revisar los supuestos epistemológicos en relación al trabajo de archivo y a problematizar la misma existencia de un organismo de las características del DIPSE, en un contexto como el santiagueño donde la movilización social y radicalización política tuvo menor intensidad que en las grandes ciudades argentinas. Historizar la práctica de la reunión de informaciones forma parte del propósito 
de conocer las instituciones a las que el archivo ha servido. Comprenderlas supone identificar a qué actores, necesidades y demandas particulares fue respondiendo el desarrollo de prácticas de investigación y vigilancia empleadas en relación a determinados sujetos y poblaciones.

En ese marco es posible comprender las categorías clasificatorias. Algunas de ellas resultan más autoevidentes como "comunismo" o "subversión", en la medida en que estas formaron parte de los discursos de seguridad nacional y fueron sancionadas además como tipos penales. Su presencia en el archivo del DIPSE se comprende por la participación de las policías provinciales dentro de un articulado institucional federal. Pero esto es solo una dimensión de la actividad del organismo. El estudio de este tipo de archivos demanda una mirada atenta a las categorías clasificatorias emergentes y que dan cuenta de los conflictos entre actores locales y las particularidades de los procesos represivos en las provincias.

De modo que el "enemigo interno", lejos de ser una categoría homogénea o unívocamente referida a las izquierdas políticas insurgentes, comprende un conjunto heterogéneo de sujetos y prácticas sociales.

Los usos del discurso del enemigo interno han permitido legitimar intervenciones policiales sobre personas por razones que serían del orden de la moralidad, por ejemplo. La deconstrucción de la mirada policial es una tarea necesaria para comprender los criterios que definen qué hechos son pasibles de ser considerados información relevante, qué recursos son considerados fuentes válidas y porqué, las concepciones de los agentes que escriben los informes y la presencia de otros patrones de clasificación y dominación que se ponen a jugar en la evaluación de qué sujetos serían merecedores de una intervención policial.

El movimiento de los DDHH y la investigación judicial de los delitos de la dictadura han posibilitado el acceso para la investigación académica a determinados archivos desclasificados. Los estudios en los campos del pasado reciente y de los llamados archivos de la represión han visto ampliados sus horizontes de indagación como consecuencia de esto. Estos archivos, a su vez, son condición de posibilidad para el análisis de las continuidades, rupturas, reformulaciones en los modos en que las agencias estales gestionan el conflicto social y político, siendo las clasificaciones una de las principales herramientas de justificación de prácticas violentas.

\section{REFERENCIAS}

Águila, G. (2013). Las tramas represivas: Continuidades y discontinuidades en un estudio de caso. La Dirección General de Informaciones de la Provincia de Santa Fe, 1966-1991. Sociohistórica, 31(26), 1-26. Recuperado de http://www.sociohistorica.fahce.unlp.edu.ar/article/view/SHn31a01/pdf. Acceso: 29 oct. 2018

Barreneche, O. (2010). Manejo metodológico de las fuentes documentales y los archivos policiales. El caso de la Policía de la Provincia de Buenos Aires. Revista Electrónica de Fuentes y Archivos del Centro de Estudios Históricos Carlos Segreti, 1, 1-17. Recuperado de https://refa.org.ar/descargas/numero-1/refa-fuentes-osvaldo-barreneche.pdf

Barreneche, O., y Galeano, D. (2008). Notas sobre las reformas policiales en la Argentina, siglos XIX y XX. Cuadernos de Seguridad, Consejo de Seguridad Interior, Ministerio de Justicia, Seguridad y Derechos Humanos, 8, 73-112. Recuperado de http://www.crimenysociedad.com.ar/wp-content/uploads/2009/03/art_barreneche_galeano-. _cuadernos_de_seguridad1.pdf Acceso: 15 mar.2016

Caimari L. (2012). Apenas un delincuente. Crimen, castigo y cultura en la Argentina, 1880-1955. Buenos Aires: Siglo Veintiuno.

Caimari, L., y Nazar, M. (2015). Detrás de una puerta gris. Notas sobre los archivos policiales públicos argentinos. En C. Aguirre y J. Villa Flores, The Destruction and Recovery of Archives and Libraries in Latin America (p. 20). Editorial A contracorriente. Recuperado de: http://www.estudiossocialesdelestado.org/index.php/ese/article/ download/151/117. Acceso: 13 sep. 2018

Chiarini, S., y Portugheis, R. (Eds.). (2014). Plan Conintes: Represión politica y sindical. Buenos Aires: Ministerio de Justicia y Derechos Humanos de la Nación. Secretaría de Derechos Humanos.

da Silva Catela, L. (2002). El mundo de los archivos. En Los archivos de la represión: Documentos, memoria y verdad (pp. 195-221). España: Siglo Veintiuno Ed. 
María Celeste Schnyder. Abrir el archivo. Reflexiones sobre la investigación en un archivo de info...

Derrida, J. (1997). Mal de archivo. Una impresión freudiana. Madrid: Trotta.

Eilbaum, L. (2004). La sospecha como fundamento de los procedimientos policiales. Cuadernos de antropología social, 20, 79-91. Recuperado de: http://revistascientificas.filo.uba.ar/index.php/CAS/article/view/4645 Acceso: 20 nov.2018

Farge, A. (1991). La atracción del archivo. Valencia: Edicions Alfons el Magnànim. Institució Valenciana d'Estudis i Investigació.

Funes, P. (2004). Medio siglo de represión. El Archivo de la Dirección de Inteligencia de la Policía de la Provincia de Buenos Aires. Revista Puentes, 4(11), 34-43.

Funes, P. (2006). Secretos, confidenciales y reservados. Los registros de las dictaduras en Argentina. El Archivo de la Dirección de Inteligencia de la Policía de la Provincia de Buenos Aires. En H. Quiroga, y C. Tcach, Argentina 1976-2006. Entre la sombra de la dictadura y el futuro de la democracia (pp. 199-232). Rosario: Homo Sapiens.

Galeano, D. (2007). En nombre de la seguridad: Lecturas sobre policía y formación estatal. Cuestiones de Sociología, 4, 102-125. http://www.memoria.fahce.unlp.edu.ar/art_revistas/pr.3679/pr.3679.pdf. Acceso: 15 mar.2014

Galvani, M. (2016). Cómo se construye un policía. La federal desde adentro. Buenos Aires: Siglo Veintiuno Ed.

Geertz C. (1991). Géneros confusos. La refiguración del pensamiento social. En C. Geertz y J. Clifford (coord.), El surgimiento de la antropologia posmoderna (pp. 63-77). España: Gedisa.

Gorbach, F., y Rufer, M. (2016). (In)Disciplinar la investigación. Archivo, trabajo de campo y escritura. México, DF: Siglo Veiniuno Ed.

Gomes Da Cunha, O. M. (2010). La existencia relativa de las cosas (que reposan en los archivos): prácticas y materialidades en relación). En Estudiar la policía. La mirada de las ciencias sociales sobre la institución policial (pp. 97-138). Buenos Aires: Teseo.

Jaschek, I., y Funes, P. (2005). De lo secreto a lo público. La creación de la DIPBA. Puentes.Revista de la Comisión Provincial por la Memoria, La Plata, 16. Recuperado de http://www.comisionporlamemoria.org/archivos/arc hivo/de-lo-secreto-a-lo-publico/dossier3.pdf

Jelin, E. (2002). Gestión política, gestión administrativa y gestión histórica: Ocultamientos y descubrimientos de los archivos de la represión. En L. da Silva y E. Jelin, Los archivos de la represión: Documentos, memoria y verdad (pp. 1-14). España: Siglo Veintiuno Ed.

Kahan, E. N. (2010). Unos pocos peligros sensatos: La Dirección de Inteligencia de la Policía de la Provincia de Buenos Aires frente a las instituciones judías de la ciudad de La Plata. Aletheia: Cuadernos Críticos Del Derecho 1(1), 5-8. Recuperado de http://www.aletheia.fahce.unlp.edu.ar/numeros/numero-1/emmanuel-n.-kahan.-unos-pocos-peligros-sens atos-la-direccion-de-inteligencia-de-la-policia-de-la-provincia-de-buenos-aires-frente-a-las-instituciones-judias -de-la-ciudad-de-la-plata

Lijterman, E. (2015). ¿Quiénes escriben los informes sociales? Un análisis de la conflictividad y el malestar en el despliegue de la 'técnica'. Plaza Pública, 13, 159-182. Recuperado en https://revistaplazapublica.files.wordpres s.com/2016/04/13-11.pdf. Acceso: 20 abril 2018

Marengo, M. E. (2015). Lo aparente como real: Un análisis del sujeto «comunista» en la creación y consolidación del servicio de inteligencia de la policia de la Provincia de Buenos Aires, 1930-1962. La Plata: Universidad Nacional de La Plata; Posadas: Universidad Nacional de Misiones; Los Polvorines: Universidad Nacional de General Sarmiento. Disponible en: http://libros.fahce.unlp.edu.ar/index.php/libros/catalog/book/35 Acceso: 30 jun.2018

Memoria Abierta, (2011). Guía de archivos útiles para la investigación judicial de delitos de lesa humanidad. Documento elaborado a propuesta de la Unidad Fiscal de Coordinación y Seguimiento de las Causas por Violaciones a los Derechos Humanos cometidas durante el Terrorismo de Estado. Buenos Aires: Memoria Abierta. Recuperado de http://memoriaabierta.org.ar/wp/wp-content/uploads/2017/08/Guia-de-archivos-M emoria-Abierta.pdf Acceso: 30 oct. 2018 
Muzzopappa, E., y Villalta, C. (2011). Reflexiones teórico-metodológicas sobre un enfoque etnográfico de archivos y documentos estatales. Revista Colombiana de Antropología, 47(1), 13-42. Recuperado en http://www.scielo.org .co/pdf/rcan/v47n1/v47n1a02.pdf. Acceso: 22 mayo 2016

Nazar, M. (2007). Dictadura, archivos y accesibilidad documental. A modo de agenda. En CELS, Derechos humanos en Argentina. Informe Anual. Buenos Aires: Eudeba.

Nazar, M. (2010). En torno a la especificidad del archivo como territorio para la investigación. Ponencia presentada en el Simposio El campo de lo estatal y sus prácticas escritas. Una vía de indagación etnográfica, Sextas jornadas sobre etnografía y métodos cualitativos, Buenos Aires, 11, 12 y 13 de agosto de 2010.

Olmo, D. (2002). Reconstruir desde restos y fragmentos: El uso de archivos policiales en la antropología forense en Argentina. En Los archivos de la represión: Documentos, memoria y verdad (pp. 179-194). España: Siglo Veintiuno Ed.

Pontoriero, E. (2016). "Preparativos de guerra": Ejército, doctrina antisubversiva y planes represivos en los orígenes del terror de Estado, 1973-1976. Revista Universitaria de Historia Militar [Faltan datos de revista]. Recuperado de https://www.researchgate.net/publication/319234307_Preparativos_de_guerra_Ejercito_doctrina_antisu bversiva_y_planes_represivos_en_los_origenes_del_terror_de_Estado_1973-1976

Rufer, M. (2016). El archivo: De la metáfora extractiva a la ruptura poscolonial. En F. Gorbach y M. Rufer, (In)Disciplinar la investigación. Archivo, trabajo de campo y escritura. México, DF: Siglo Veintiuno Ed.

Sain, M. (1997). Condiciones institucionales para el control parlamentario de las actividades y organismos de inteligencia del Estado. En Control democrático de los organismos de seguridad interior en la república Argentina. Buenos Aires: CELS.

Sarrabayrouse Oliveira, M. J. (2009). Reflexiones metodológicas en torno al trabajo de campo antropológico en el terreno de la historia reciente. Cuadernos de Antropología Social, 29, 61-83. Recuperado de: http://revistascient ificas.filo.uba.ar/index.php/CAS/article/view/2795. Acceso: 13 sep. 2018

Stoler, A. L. (2010). Archivos coloniales y el arte de gobernar. Revista Colombiana de Antropología. Instituto Colombiano de Antropología e Historia Bogotá, Colombia, 46(2), 465-496. Recuperado de http://www.scielo.org .co/scielo.php?script=sci_arttext\&pid=S0486-65252010000200010\&lng=en\&tlng=es. Aceso: 20 noviembre 2018.

Summo, M. y Pontoriero, E. (2012). Pensar la "guerra revolucionaria": doctrina antisubversiva francesa y legislación de defensa en la argentina (1958-1962). Cuadernos de Marte, año 2, 3, p. 285-305. Recuperado de: http://www .iigg.sociales.uba.ar/revistacuadernosdemarte. Acceso:19 ago.2018

Vitale, M. A. (2017). Análisis del discurso y archivos de la represión en Argentina. Revista Conexão Letras - Programa de Pós-Graduação em Letras da Universidade Federal do Rio Grande do Sul, 12(18), 53-62. https://doi.org/10. 22456/2594-8962.79456. Acceso: 20 noviembre 2018.

\section{Notas}

1 La Dirección de Inteligencia de la Policía de la Provincia de Buenos Aires (DIPPBA) es el primer fondo documental de los servicios de inteligencia abierto a la consulta pública en la Argentina.

2 La SIDE fue creada para "realizar actividades informativas y producir inteligencia en interés de la seguridad de la Nación, para la conducción de los asuntos de Estado y para la acción contra el comunismo”. Decreto N. ${ }^{\circ} 776 / 56$. A diferencia de su antecesora, la Coordinación de Informaciones de Estado (1946), que tuvo la función de "suministrar al poder ejecutivo nacional y demás organismos del estado las informaciones que se consideren útiles o les sean requeridas, centralizando y coordinando las que se originen en los servicios especializados y en los organismos gubernamentales" (decreto 337/1946). Extraído de Sain (1997, p. 146).

3 Ese destacamento tenía asiento en Tucumán (subzona 3.2) que dependía de la Jefatura de Inteligencia del Ejército de la V Brigada, perteneciente a la Jefatura de Inteligencia del III Cuerpo del Ejército.

\section{BY-NC-SA}

